\title{
Aplikasi Bot Akademik BAAK STMIK Jakarta STI\&K Platform Line Messenger Menggunakan Go Languages
}

\author{
Melani Dewi Lusita ${ }^{1}$, Hurnianingsih ${ }^{2}$, Erni Rihyanti ${ }^{3}$ \\ ${ }^{1}$ Prodi Sistem Informasi STMIK Jakarta STI\&K \\ Jl. BRI Radio Dalam No. 17 Kebayoran Baru Jakarta Selatan-12240 (021-7397973) \\ ${ }^{2,3}$ Fakultas Teknik Industri Universitas Gunadarma \\ Jl. Margonda Raya 100, Depok, Jawa Barat, INDONESIA - 16424. 021 - 78881112 \\ e-mail: ${ }^{1}$ melanilusita@gmail.com, ${ }^{2}$ hurni@staff.gunadarma.ac.id, ${ }^{3}$ erni.rihyanti@gmail.com \\ Submitted Date: January $13^{\text {th }}, 2020$ \\ Reviewed Date: January $14^{\text {th }}, 2020$ \\ Revised Date: January $28^{\text {th }}, 2020$ \\ Accepted Date: January $31^{\text {st }}, 2020$
}

\begin{abstract}
BAAK Jakarta STMIK Campus STI \& K or the Academic and Student Administration Bureau is a bureau that handles everything related to organizing teaching and learning activities at the STMIK Jakarta STI \& K Campus. Problems with the services provided on the site include, among other things, class schedules, exam schedules, academic news, academic calendars, KRS (Study Plan Card) filling schedules and others. The method in this study uses the waterfall in designing BOT applications based on the Line Messenger platform. The results of this study are to facilitate and expand student access to obtain services from BAAK. Not only makes it easy to get information about academics at the STMIK Jakarta STI \& K Campus, but also makes it easy to share that information with friends.
\end{abstract}

Keywords: BOT, Line Messenger, STMIK Jakarta STI\&K

\begin{abstract}
Abstrak
BAAK Kampus STMIK Jakarta STI\&K atau Biro Administrasi Akademik dan Kemahasiswaan adalah suatu biro yang menangani segala sesuatu yang berkaitan dengan penyelenggaraan kegiatan belajarmengajar di Kampus STMIK Jakarta STI\&K. Masalah pada pelayanan yang diberikan di situsnya adalah antara lain seperti jadwal kuliah, jadwal ujian, berita seputar akademik, kalender akademik, jadwal pengisian KRS (Kartu Rencana Studi) dan lainnya. Metode pada penelitian ini menggunakan waterfall dalam merancang aplikasi BOT berbasis platform Line Messenger. Hasil penelitian ini adalah memudahkan dan memperluas akses mahasiswa dalam memperoleh layanan dari BAAK. Tidak hanya mempermudah dalam memperoleh informasi seputar akademik di Kampus STMIK Jakarta STI\&K, namun juga memudahkan dalam membagi informasi tersebut kepada teman.
\end{abstract}

Kata Kunci: BOT, Line Messenger, STMIK Jakarta STI\&K

\section{Pendahuluan}

Line bot adalah program komputer yang termasuk kedalam chatbot dan dijalankan di lingkungan Line messenger yang khusus dibuat untuk melakukan pekerjaan-pekerjaan otomatis seperti mengirim pesan otomatis kepada user, menjawab pesan user, dan membuat game. Chatbot adalah sebuah aplikasi komputer yang dikembangkan untuk membantu percakapan antara satu atau lebih manusia dalam bentuk audio maupun teks. Line messenger adalah sebuah aplikasi pengiriman pesan instan yang digunakan di banyak platform seperti telepon cerdas, tablet, dan komputer.

Fitur pada Line bot ada yang disebut dengan Messaging Application Programming Interface (API) yang memungkinkan komunikasi dua arah antara layanan dari server dan pengguna Line messenger. Messaging API bekerja dengan mengirim dan menerima data antara server pembuat dan aplikasi Line messenger melalui server Line messenger. Permintaan dikirim melalui API dalam format JavaScript Object Notation (JSON). Ada pula fitur yang disebut Push API dan Reply API, dimana Push API digunakan untuk 
mengirim pesan kepada pengguna menggunakan Bot dengan pemilihan waktu yang ditentukan, sedangkan Reply API merupakan API untuk mengirim jawaban atas pesan yang dikirim oleh pengguna. (Yudi Irawan Candra, Kosdiana 2019)

Biro Administrasi Akademik dan Kemahasiswaan (BAAK) merupakan suatu biro bertugas menangani semua kegiatan yang berkaitan dengan kegiatan penyelenggaraan belajar mengajar dan administrasi akademik untuk seluruh mahasiswa STMIK Jakarta STI\&K. Salah satu layanan dari BAAK terdapat pada situs resminya di baak.jak-stik.ac.id yang merupakan salah satu sub domain kampus yang cukup ramai digunakan oleh mahasiswa STMIK Jakarta STI\&K. Informasi akademik yang terdapat pada situs BAAK tersebut meliputi informasi jadwal perkuliahan, jadwal pengisian Kartu Rencana Studi (KRS), informasi mahasiswa, kalender akademik, dan hal lain yang berhubungan dengan akademik. Meskipun dengan adanya situs online BAAK tersebut mahasiswa sudah dapat memperoleh informasi relatif mudah,namun kenyataannya masih banyak terdapat mahasiswa yang malas untuk membuka situs tersebut. Mahasiswa lebih sering bertanya kepada temannya di sosial media khususnya aplikasi Line messenger ini. Hal tersebut merupakan salah satu yang melatar belakangi penelitian ini, dan begitu populernya aplikasi Line messenger ini dan hampir setiap mahasiswa memiliki akun Line messenger di smartphonenya.

Aplikasi ini dapat mempercepat dan juga mempermudah dalam mendapatkan informasi akademik kampus yang diinginkan. Aplikasi ini dibuat dengan bahasa pemrograman Go (GoLang). Hal yang melatar belakangi dibuat dengan GoLang adalah karena SDK (Software Development Kit) dalam bahasa Go telah di support oleh Line bot, selain itu agar dapat lebih memotivasi peneliti dalam mempelajari bahasa Go.

\section{Referensi Pustaka}

Line merupakan suatu aplikasi gratis yang dapat digunakan mengirim pesan teks, pesan suara, panggilan suara, gambar dan video melalui koneksi internet. Line bisa beroperasi pada bagian platform seperti tablet, smartphone maupun notebook atau komputer. Namun Line lebih populer pada smartphone Android, Apple, dan Blackberry.

Line adalah media social dalam bentuk aplikasi chating sedang populer di dunia. Line dikembangkan sekitar bulan Maret 2011 line chat sekarang anggotanya 300 juta pengguna di seluruh dunia dan 14 juta pemakai aktif berada di Indonesia. Line chat memiliki keunikan tersendiri karena menggunakan emoticon yang inovatif dalam bentuk Stiker. Line juga menawarkan fiturfitur lain seperti line games, line camera, line shoping di dalamnya.

Aplikasi LINE menggunakan nomor telepon seluler sebagai media untuk saling berhubungan. Aplikasi ini tersedia untuk perangkat yang menggunakan sistem operasional iOS dan Android. Aplikasi Line diunduh gratis dalam App Store dan Google Play. Aplikasi Line sangat berbeda dari aplikasi IM lainnya perbedaannya adalah karena ada emoticon bervariasi. Bentuk Emosi tersebut ada yang menggambarkan wajah bermacam ekspresi. Emoticons lain berupa susunan karakter teks juga membentuk ekspresi. Bentuk lain berupa stickers yang cukup unik pada aplikasi Line karena bentuk ikonnya lucu-lucu, lebih ekpresif dan berukuran besar. (Karmila, Mahyuzar, 2020,)

\subsection{Golang (Go Language)}

Bahasa Golang atau biasa disebut Go merupakan bahasa pemrograman dikembangkan di Google oleh Rob Pike, Robert Griesemer, dan Ken Thompson tahun 2007. Namun Bahasa ini diperkenalkan di publik tahun 2009. Bahasa Golang dibuat berdasarkan bahasa $\mathrm{C}$ dan $\mathrm{C}++$ sehingga gaya sintaks-nya mirip. Golang memiliki beberapa kelebihan: Mendukung konkurensi di level bahasa dengan pengaplikasian cukup mudah. Bahasa ini mendukung pemrosesan data oleh banyak prosesor di waktu bersamaan (pararel processing). Memiliki garbage collector dengan proses kompilasi sangat cepat.

Bukan bahasa pemrograman yang hirarkial, menjadikan developer tidak perlu ribet memikirkan segmen OOP (Object Oriented Programming) Package/modul yang disediakan terbilang lengkap. Bahasa Goalang ini bersifat open source, sehingga banyak sekali para pengembang juga mengembangkan modul-modul tambahan untuk bisa dimanfaatkan. Meskipun bahasa ini masih terbilang baru, sudah banyak industri dan perusahaan yang menggunakan Golang sampai level production, termasuk diantaranya adalah Google sendiri. (Agung Noval, 2017)

\subsection{API (Application Programming Interface)}

API adalah aplikasi interface yang terdiri atas banyak instruksi dan disimpan dalam bentuk library. API ini menjelaskan bagaimana suatu software dapat berinteraksi dengan software lain. Penjelasan ini dapat dicontohkan dengan analogi apabila akan dibangun suatu rumah. Dengan menyewa kontraktor yang dapat menangani bagian 
yang berbeda, pemilik rumah dapat memberikan tugas yang perlu dilakukan oleh kontraktor tanpa harus mengetahui bagaimana cara kontraktor menyelesaikan pekerjaan tersebut.

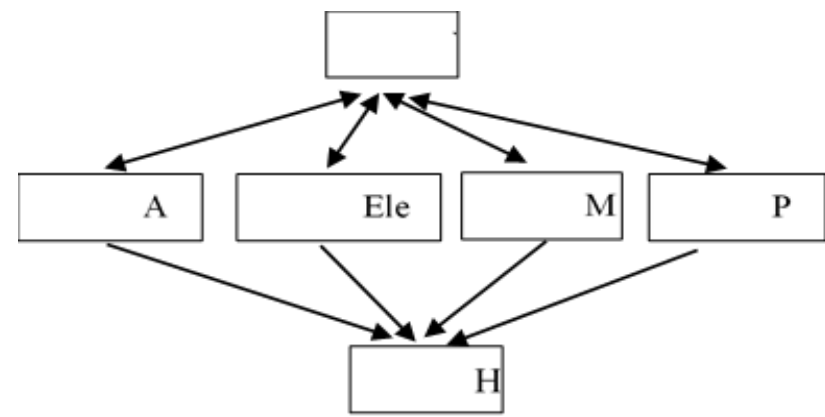

Gambar 1 Analogi API

Interface pada perangkat lunak adalah entry points untuk digunakan mengakses semua resources yang terdapat didalam software tersebut. Aplikasi API mempunyai aturan bagaimana software dapat berinteraksi dengan software lain yaitu dengan mengakses resources melalui interface yang ada.

API struktural adalah spesifikasi dari suatu data structure, function, objects, beserta banyak parameter yang digunakan untuk mengakses resource aplikasi tersebut. Seluruh spesifikasi tersebut membentuk suatu interface yang dimiliki oleh aplikasi untuk berkomunikasi dengan aplikasi lain, dan API dapat digunakan dengan berbagai bahasa programming, ataupun hanya dengan menggunakan URL (Uniform Resource Locator) yang telah disediakan oleh suatu website. (Binus Library, 2017)

\subsection{Format JSON}

JSON atau Javascript Object Notation merupakan bentuk pertukaran data sangat ringan, mudah dibaca atau ditulis manusia. JASON mudah diterjemahkan digenerate menggunakan program komputer. Format JASON dibuat berdasarkan Bahasa Pemrograman JavaScript Standar ECMA262 Edisi ke 3 Desember 1999. JSON mempunyai format teks tidak bergantung dengan bahasa pemrograman tertentu. JASON menggunakan gaya bahasa umum digunakan oleh programmer keluarga $\mathrm{C}$ termasuk $\mathrm{C}++$, Java, JavaScript, perl, python. JASON sangat ideal sebagai Bahasa pertukaran data karena memiliki sifat-sifat tersebut. (Rian Satria, 2017)

\subsection{Line Bot}

Line bot adalah program komputer yang termasuk kedalam chatbot dan dijalankan di lingkungan Line messenger yang khusus dibuat untuk melakukan pekerjaan-pekerjaan otomatis seperti mengirim pesan otomatis kepada user, menjawab pesan user, dan membuat game.

Chatbot adalah sebuah aplikasi komputer yang dikembangkan untuk membantu percakapan antara satu atau lebih manusia dalam bentuk audio maupun teks. Aplikasi Line messenger merupakan aplikasi pengiriman pesan instan yang digunakan banyak jenis platform seperti telepon cerdas, tablet, dan komputer. (Ananda Dwi R, Firdha Imamah, Yusuf Mei Andre S, Ardiansyah, 2018)

\subsection{Server VPS}

Layanan web hosting adalah Salah satu penggunaan yang cukup populer dari VPS. Virtual Private Server sangat tepat untuk mengatasi kebutuhan website kelas menengah maupun corporate, dimana pada umumnya aplikasi-aplikasi web membutuhkan konfigurasi yang spesifik dan hanya bisa dilakukan oleh Superuser (Administrator pada Dos, Root pada keluarga *nix). Penggunaan ini juga cocok bagi yang ingin memulai bisnis web.

hosting dengan anggaran yang terbatas, namun ingin memberikan layanan yang berkualitas. Adanya variasi paket (spesifikasi) VPS memungkinkan bagi pelaku bisnis web hosting bisa dengan mudah melakukan upgrade sewaktu-waktu sejalan dengan bertambahnya customer baru. Application Server, VPS memungkinkan penggunanya dapat menyediakan layanan khusus yang membutuhkan instalasi suatu perangkat lunak (application) tertentu. (Ricky Eka P, Andy Rachman, Tri Wahyu H, 2010)

\subsection{MySql}

MySQL adalah software system manajemen database atau Database Management SystemDBMS yang sangat popular digunakan para pembuat program Web. MyAQL banyak digunakan terutama di lingkungan Linux dengan menggunakan script PHP dan perl software. Database ini telah tersedia juga pada platform system operasi Windows (98/ME ataupun NT/2000/XP) sebagai sumber dan pengelolaan datanya.

\subsection{Unified Modeling Language}

UML merupakan sistem arsitektur yang bekerja dalam OOAD (Object-Oriented Analysis/Design) dengan satu bahasa yang 
konsisten untuk menentukan, visualisasi, mengkontruksi, dan mendokumentasikan artifact atau sebuah informasi. UML digunakan atau menghasilkan suatu proses rekayasa software, dapat berupa model, deskripsi, atau software yang terdapat dalam sistem software. UML merupakan bahasa pemodelan yang paling sukses dari tiga metode $\mathrm{OO}$ yang telah ada sebelumnya, yaitu Booch, OMT (Object Modeling Technique), dan OOSE (Object-Oriented Software Engineering). (Ade Hendin, 2016)

\section{Metode Penelitian}

Metode penelitian berdasarkan artikelartikel maupun akademi yang di sediakan di situs internet guna mempelajari mulai dari pengenalan sampai membuat sample aplikasi. Selain itu terdapat juga dokumentasi resmi yang telah disediakan oleh pengembang khusus untuk developer. Kemudian mempelajari struktur yang ada di situs BAAK lalu di integrasikan dengan program Bot yang akan dibuat.Metode yang dilakukan dalam penelitian ini adalah sebagai berikut :

1. Fase Pengumpulan Data, Tahap ini merupakan tahap untuk mengumpulkan data maupun referensi yang dibutuhkan. Sumber referensi didapatkan dari akademi online yang menyediakan pelatihan secara online dan berbagai artikel mengenai bot Line messenger.

2. Fase Perancangan Line Bot, Tahap perancangan Line bot dan menghubungkan dengan API yang telah dibuat pada tahap sebelumnya.

3. Fase Implementasi, Pada tahap ini dilakukan pengujian dengan menggunakan aplikasi Line messenger.

\section{$4 \quad$ Hasil Dan Pembahasan}

\subsection{Perangkat Software dan Hardware}

Pada tahap ini dijabarkan perangkat lunak dan perangkat keras apa saja yang digunakan. Perangkat lunak yang digunakan, antara lain:

1. Sistem Operasi Linux Ubuntu 64-bit

2. Golang 1.8.3

3. Nginx Server

4. Sublime Text 3

5. Aplikasi Line Messenger mobile versi 7.11.2

6. Mozilla Firefox

7. Mosh Shell

Sedangkan perangkat keras pada saat pengujian, antara lain:
1. Laptop Lenovo Y410p Ideapad, INTEL i7, NVIDIA Geforce 755, RAM 8GB

2. Smartphone Xiaomi Redmi 4x, android 6.0 Marshmalow

3. Virtual Private Server (VPS) OVH, Ubuntu 64-bit

4. 2GB RAM, 10GB SSD

\subsection{Perancangan UML}

Unified Modelling Language atau disebut dengan UML ini berfungsi untuk menampilkan secara visual interaksi antara user dengan sistem. Perancangan sistem atau desain sistem dilakukan dengan memodelkan permasalahan dalam bentuk diagram-diagram UML sebagai berikut.

\subsection{Use Case Diagram}

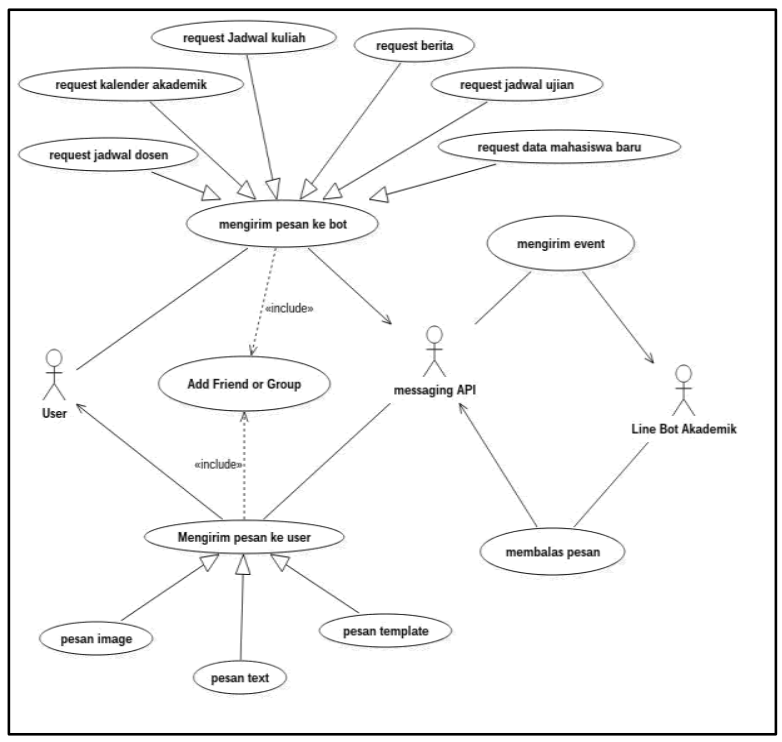

Gambar 2 Use Case Diagram Bot Akademik

Use Case Diagram menggambarkan fungsionalitas keseluruhan dari sebuah sistem, yaitu membuat gambaran mengenai interaksi antara aktor dan sistem. Pada Line Bot Akademik ini user dapat meminta jadwal kuliah, jadwal ujian, kalender akademik, berita, jadwal dosen, data mahasiswa baru dengan mengirimkan pesan kepada bot. Pesan tersebut dapat diterima oleh Messaging API dan kemudian diteruskan ke program. Setelah itu program kemudian membalas sesuai request yang diminta user baik berupa image, text, atau template message. User dapat menggunakan Line Bot Akademik hanya dengan cara menambahkannya sebagai teman atau menambahkannya ke dalam grup/room. 


\subsection{Persiapan penggunaan API}

Sebelum membuat program, langkah yang harus dilakukan terlebih dahulu adalah membuat akun Line@ untuk Bot yang dibuat. Akun tersebut digunakan untuk mengatur segala yang berhubungan dengan Line bot seperti secret key, nama bot, dan sebagainya.

\subsection{Akun Line Business}

Pertama, login terlebih dahulu di website line business center yang beralamat di https://business.line.me/id/. Kemudian klik tombol login yang terletak di pojok sebelah kanan.

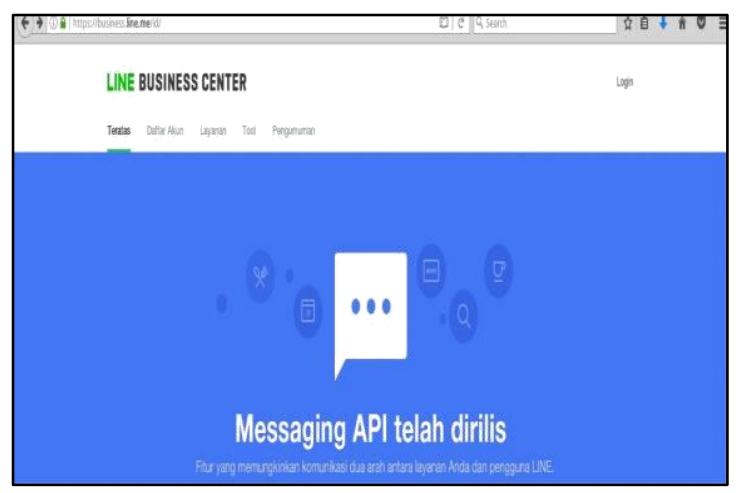

Gambar 3 Web Line Business

Setelah itu login menggunakan akun Line Messenger yang sudah ada. Pada saat awal mula membuat akun line business ini, jika tidak dapat masuk, maka harus mendaftarkan email terlebih dahulu melalui aplikasi Line messenger di smartphone. Pengaturannya terletak pada menu paling kanan (gambar titik tiga) lalu klik settings pada pojok kanan atas, seperti terlihat pada gambar berikut.

\begin{tabular}{|l|}
\hline Settings \\
My info \\
1 Edit profile \\
후 Account \\
\hline
\end{tabular}

Gambar 4 Profile Settings

Kemudian pada menu settings pilih "Account" dan pilih lagi "Email Registration". Setelah itu masukkan email yang di registrasi, berikut: password dan konfirmasi psasword.
Apabila email sudah sukses terdaftar, selanjutnya login kembali ke website "Line Business Center" dan kemudian di minta untuk melakukan verifikasi kode lewat aplikasi Line mobile.

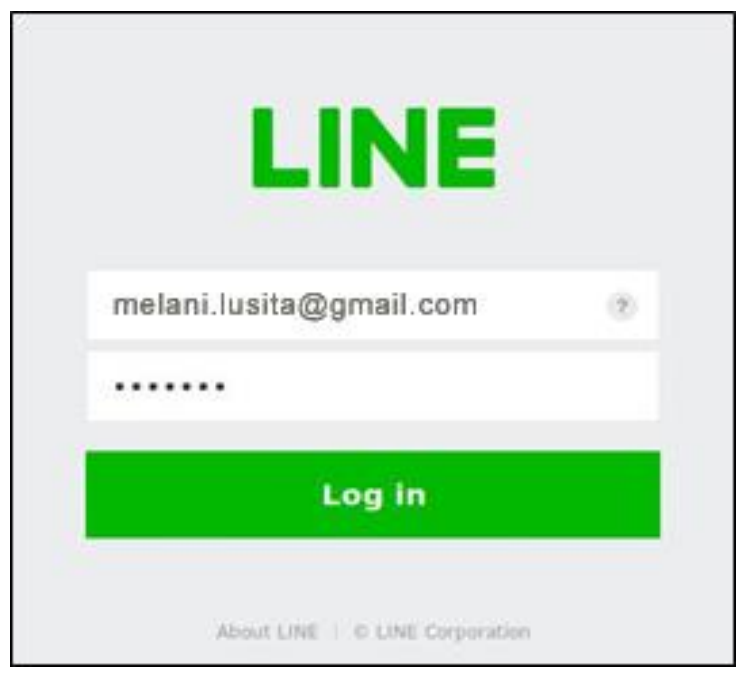

Gambar 5 Line Login

\subsection{Membuat Akun Messaging API}

Untuk memulai messaging API pilih tombol Developer Trial. Kemudian pilih akun yang telah dibuat sebelumnya, sebagai contoh akun peneliti adalah sadan. Opsi Developer trial merupakan messaging API yang tidak berbayar, namun bot yang dibuat hanya dapat memiliki teman/user sebanyak 50 saja.

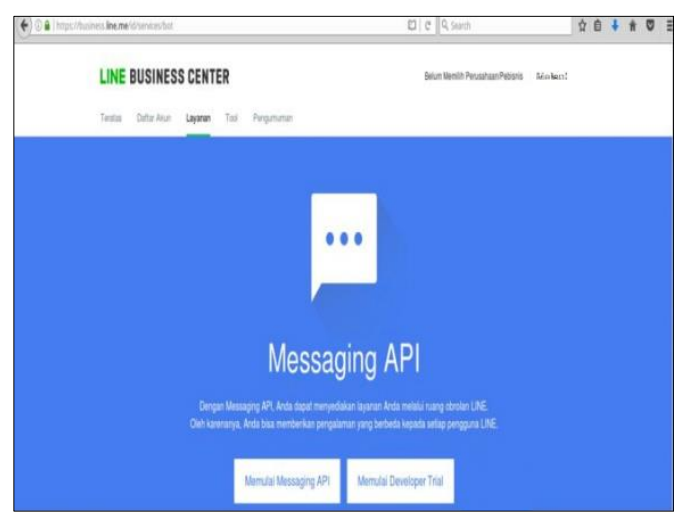

Gambar 6 Membuat akun Messaging API

\subsection{Konfigurasi Pada Akun Bot dan Channel}

Setelah bot telah aktif, masih pada halaman messaging api settings kini menampilkan form pengaturan mengenai bot. Terdapat 4 opsi yang diatur pada halaman ini: Pada option Use Webhooks, pilih opsi Allow. Pada bagian ini digunakan agar kita dapat mendaftarkan URL Webhook sebagai alamat tujuan pengiriman 
informasi notifikasi dari platform LINE ke aplikasi di server. Pada bagian Allow Bot to join group chat, pilih opsi Allow, Option ini digunakan agar bot dapat di masukkan ke grup chat. Pada bagian Auto Reply Message, pilih opsi Don't Allow, agar bot tidak mengirimkan pesan balasan default untuk setiap pesan chat yang dikirimkan oleh pengguna. FItur ini dimatikan karena pesan kemudian dibalas menggunakan program tersendiri. Pada bagian Greeting Message, pilih opsi Don't Allow karena bot memberi greeting message melalui program yangakan dibuat.

Setelah membuat akun Line Business, kita mendapatkan Channel Access Token, yakni string yang digunakan sebagai identitas aplikasi saat melakukan request ke platform Line. Token ini digunakan oleh platform Line untuk mengenali akun bisnis kita, sebagai tanda pengenal bahwa request kita valid. Channel Secret, yakni string yang kita gunakan untuk memastikan bahwa setiap request yang masuk ke aplikasi kita melalui URL webhook adalah benar dari platform Line.

\subsection{Setting Up Server}

Mempersiapkan server tidak harus dilakukan pada tahap akhir atau deploy saja. Karena pada program ini membutuhkan aplikasi Line messenger yang tentunya harus online untuk melihat apakah setiap tahapan berhasil atau terdapat kesalahan (error). Server yang digunakan adalah berupa virtual (VPS) dengan sistem operasi Ubuntu 16.04.2 LTS.

Hal pertama yang harus dilakukan adalah menginstall terlebih dahulu bahasa yang digunakan pada program yang dibuat yaitu Golang. Membuat service berguna agar program selalu di jalankan pada proses startup pada server. Caranya dengan membuat sebuah startup script dan di letakkan pada folder init.d. Sebagai contoh peneliti membuat startup script dengan nama linebot.sh.

Setup Nginx Server web server merupakan salah satu hal yang penting dalam pembuatan program Line bot ini. Untuk melakukan instalasi web server pada sistem operasi ubuntu adalah dengan memasukkan perintah di bawah ini.

Setelah memiliki dan melakukan konfigurasi pada sebuah web server, langkah selanjutnya adalah install MySQL untuk menyimpan data dan mengelola data tersebut.

\subsection{Pembuatan Program}

Setelah database selesai dibuat, tahap selanjutnya adalah membuat program untuk Line bot. Editor yang digunakan oleh peneliti pada komputer lokal adalah Sublime text 3 dengan plugin GoSublime. Terdapat beberapa file utama dalam program Line bot akademik.

Tabel 1 File program yang dibuat

\begin{tabular}{|c|l|}
\hline Nama file & \multicolumn{1}{|c|}{ Fungsi } \\
\hline Main.go & $\begin{array}{l}\text { File ini merupakan file utama } \\
\text { yang berfungsi sebagai main dari } \\
\text { program Line bot }\end{array}$ \\
\hline Models.go & $\begin{array}{l}\text { File ini berfungsi sebagai models } \\
\text { dari database atau file yang berisi } \\
\text { struct dan variabel baik yang } \\
\text { bersifat global dan juga struct } \\
\text { untuk menampung value dari } \\
\text { database }\end{array}$ \\
\hline Message.go & $\begin{array}{l}\text { File ini berfungsi untuk } \\
\text { menghandle dan mengirim } \\
\text { pesan dari program sampai ke } \\
\text { aplikasi Line }\end{array}$ \\
\hline Akademik.go & $\begin{array}{l}\text { File ini berisi functions } \\
\text { untuk melakukan query ke } \\
\text { database }\end{array}$ \\
\hline
\end{tabular}

Membuat database berisi data jadawal. Data jadwal kemudian ditampilakn dalam bentuk HTML. Pada file ini akan menghasilkan output sebuah tabel yang berisikan jadwal kuliah yang sudah didapatkan dari database.

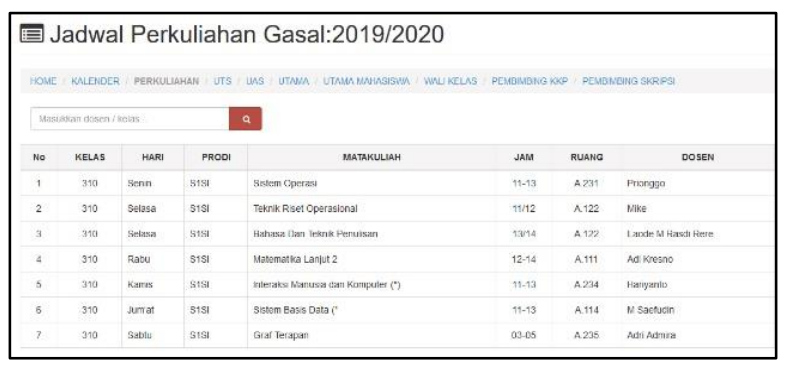

Gambar 7 Hasil file HTML

\subsection{Uji Coba}

Pada sub-bab ini peneliti akan melakukan uji coba terhadap program Line bot yang telah dibuat. Peneliti mencoba program ini pada aplikasi Line versi mobile/smartphone. Pertama Tambahkan dahulu Bot Akademik sebagai teman, dengan mencari berdasarkan id Line@. 


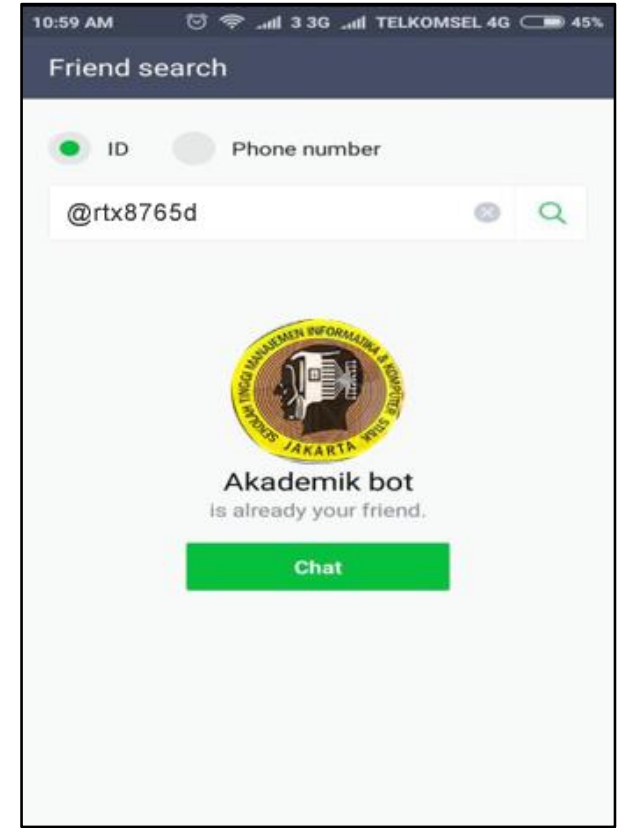

Gambar 8 Mencari bot berdasarkan id

Setelah ditambahkan sebagai teman selanjutnya Bot Akademik kemudian mengirim sebuah pesan

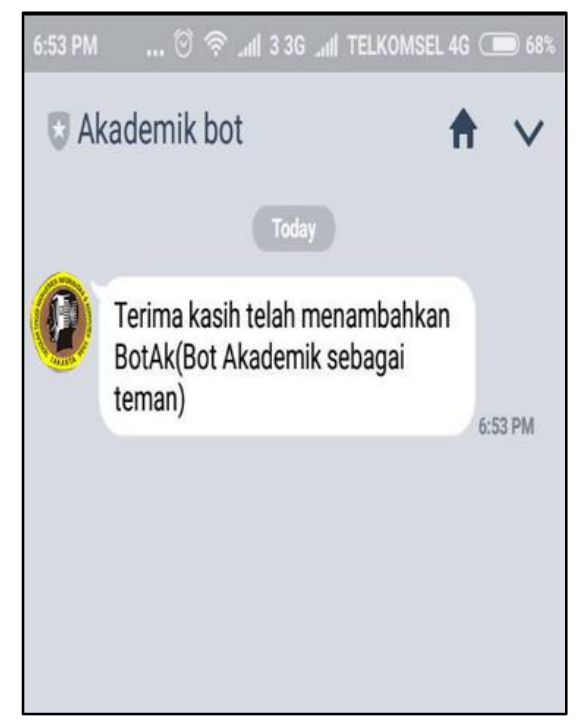

Gambar 9 Menambahkan bot di chat personal

Sebagai contoh peneliti meminta sebuah jadwal kuliah untuk kelas 310, untuk berbicara pada bot harus di awali @ bot di ikuti jadwal kelas, seperti di bawah ini.

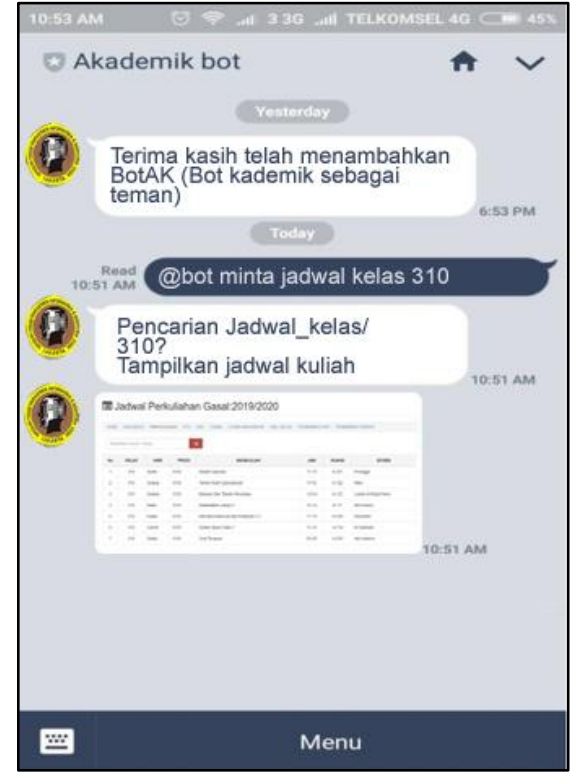

Gambar 10 Request jadwal kuliah

\section{5 kesimpulan}

Berdasarkan Hasil uji coba, peneliti dapat membuat Line Bot Akademik berjalan pada personal chat maupun chat pada grup. Terdapat beberapa tahapan yang harus dilakukan sebelum membuat program seperti menentukan kebutuhan software dan hardware, merancang use case diagram, membuat akun Line@ dan setting up server. Akun Line@ yang peneliti buat hanyalah versi trial dari Line @. Akun yang dapat menggunakan Line Bot Akademik ini hanya sebanyak 50 user saja.

Setting up server dilakukan di awal sebelum pembuatan program karena agar terkoneksi dengan Messaging API milik Line Messenger, program harus sudah online dan memiliki sertifikat SSL atau HTTPS. Karena sebab itu program Line Bot ini tidak dapat di jalankan pada lokal secara sempurna. Pada hasil uji coba sebelumnya dapat dilihat bahwa Line Bot yang dapat di tambahkan ke dalam grup hanyalah 1 buah bot saja, apabila menambahkan lebih dari satu, maka salah satu dari bot tersebut tidak berjalan sesuai fungsinya.

\section{Referensi}

Karmila, Mahyuzar, 2020, Jurnal Ilmiah Mahasiswa Fakultas Ilmu Sosial \& Ilmu Politik, Pemanfaatan Media Sosial Grup Messenger Line di Kalangan Mahasiswa Dalam Mendapatkan Informasi Perkuliahan (Studi pada Poilitik Universitas Syiah Kuala)

Agung, Noval. 2017. Dasar Pemrograman Golang, Ebook 
Binus Library. 2017. API (Application Programming Interface), Ebook Thesis, Universitas Bina Nusantara

Satria, Rian. 2017. JSON, Ebook Universitas Komputer Indonesia.

Ananda Dwi R, Firdha Imamah, Yusuf Mei Andre S, Ardiansyah, Jurnal Cendikia Vol. XVI Cendikia 2018 Bandar Lampung, Oktober 2018, Aplikasi Chatbot(Milki Bot) Yang Terintegrasi Dengan Web Cms untuk Customer Servicepada Ukm Minsu.

Ricky Eka P, Andy Rachman, Tri Wahyu H, 11th Seminar on Intelligent Technology and Its Applications, SITIA 2010, Virtual Private Server (VPS) Sebagai Alternatif Pengganti Dedicated Server,

Yudi Irawan Candra, Kosdiana, 2019, Prosiding Seminar Nasional Teknologi Informasi dan Komunikasi STI\&K (SeNTIK) Volume 3 Nomor 1, 22 Agustus 2019, ISSN : 2581-2327, Rancang Bangun Aplikasi Chat Bot Line Menggunakan Pendekatan Agile Process Dengan Model Extreme Programming Berbasis Web

Ade Hendin, Pemodelan UML Sistem Informasi Monitoring penjualan Dan Stok Barang (Studi Kasus: Distro zhezha pontianak) Jurnal Khatulistiwa Informatika, Vol. Iv, No.2 Desember 2016 